ANUARIO DE ESTUDIOS MEDIEVALES

42/2, julio-diciembre de 2012, pp. 755-769

ISSN 0066-5061

doi:10.3989/aem.2012.42.2.16

\title{
LA INVASIÓN MUSULMANA DE LA PENÍNSULA IBÉRICA EN EL AÑO 711 Y LA FLOTA DE IFRIQIYA ${ }^{1}$
}

\author{
THE MUSLIM INVASION OF THE IBERIAN PENINSULA \\ IN THE YEAR 711 AND THE FLEET OF IFRIQIYA
}

\author{
JULIA MONTENEGRO \\ Universidad de Valladolid \\ ARCADIO DEL CASTILLO \\ Universidad de Alicante
}

\begin{abstract}
Resumen: La invasión del reino visigodo de Toledo fue resultado del propio expansionismo musulmán, pero la posibilidad real y la facilidad con la que se llevó a cabo fue consecuencia del pacto con don Julián y de la ayuda de la facción witizana. Pero, desde luego todo indica que no participó en un principio la flota musulmana de Ifriqiya, pese a la interpretación que algunos hacen de varias referencias de ciertos autores musulmanes. Consideramos que los barcos en los que Ayyash (Abbas) Ibn Sharahil (Uŷayl, Ajyal) se trasladó desde Al-Andalus hasta Ifriqiya eran los que Muza Ibn Nusayr había mandado construir en gran número en la orilla africana después de la partida de Tariq Ibn Ziyad a la península Ibérica, los cuales fueron utilizados para enviar refuerzos a éste, así como para que el mismo Muza pudiera atravesar el estrecho de Gibraltar en el año 93 de la Hégira y también para transportar hasta Tánger el botín de guerra que Muza se llevó en el año 95 de la Hégira.
\end{abstract}

Palabras clave: península Ibérica; invasión musulmana; flota musulmana de Ifriqiya; fuentes musulmanas; fuentes cristianas.

\begin{abstract}
Abtract: The invasion of the Visigothic Kingdom of Toledo came about through the expansion of the Muslim Empire, but the real possibility and ease with which it occurred was brought about by the pact made with Count Julian and the help of the Witizan faction. Everything seems to indicate that the Muslim fleet of Ifriqiya did not participate initially, despite the interpretation made by some, of several references from certain Muslim authors. We believe that the ships in which Ayyash (Abbas) Ibn Sharahil (Ujayl, Akhyal) sailed from Al-Andalus to Ifriqiya were those that Musa Ibn Nusayr had built in vast numbers on the shores of Africa, after Tariq Ibn Ziyad set sail for the Iberian Peninsula, and which were used to send him reinforcements, so that Musa himself could cross the Straits of Gibraltar in the year 93 of the Hegira, and also to transport the spoils of war that Musa took to Tangier in the year 95 of the Hegira.
\end{abstract}

Keywords: Iberian peninsula; Muslim invasion; Muslim fleet of Ifriqiya; Muslim sources; Christian sources.

${ }^{1}$ Ha sido posible llevar a cabo este trabajo gracias a la consulta de los fondos del Warburg Institute, la School of Oriental and African Studies y la British Library durante nuestra estancia en Londres en enero de 2011. 


\section{SUMARIO}

1. Ayyash (Abbas) Ibn Sharahil (Uŷayl).-2. Ayyash Ibn Ajyal.- 3. Expedición marítima a Cerdeña.- 4. La invasión de la península Ibérica.- 5. Aspectos de la desaparición del reino visigodo de Toledo.- 6. La invasión no estaba programada.- 7. Conclusión.- 8. Bibliografía citada.

En un trabajo publicado en 1987 Pierre Guichard, basándose en una referencia de Al-Dabbi, consideró (aunque con algunas dudas) que la flota musulmana de Ifriqiya pudo haber participado en el desembarco de las tropas musulmanas en la península Ibérica en el año $711^{2}$. Posteriormente, Jorge Lirola Delgado defendió el mismo criterio, manteniendo que sin ninguna duda la invasión de la península Ibérica sólo fue posible, inicialmente, gracias a la participación de dicha flota, y además puso de manifiesto que la referencia de Al-Dabbi se encontraba igualmente en otros autores, a saber, Al-Humaydi e Ibn Abd Al-Malik Al-Marrakushi ${ }^{3}$.

No compartimos tal idea, pues estimamos que lo indicado por Al-Humaydi, AlDabbi e Ibn Abd Al-Malik Al-Marrakushi no puede llevarnos a considerar, como apunta Pierre Guichard y asegura Jorge Lirola Delgado, que la flota de Ifriqiya pudiese haber participado en la invasión de la península Ibérica por Tariq Ibn Ziyad en abril del 711.

\section{AYYASH (ABBAS) IBN SHARAHIL (UŶAYL)}

Veamos, por orden cronológico, lo que realmente dicen tales autores: AlHumaydi, siguiendo a Said Ibn Al-Musayyab (m. 715), dice que Ayyash Ibn Sharahil Al-Himyari (fue) valí del mar en la época de los Omeyas; y que entró en Al-Andalus, y vino en barcos desde Al-Andalus a Ifriqiya, en el año 100 (3 de agosto de 718 a 23 de julio de 719). Y que a tal conclusión llegó, tras haber investigado en varias fuentes de la Historia de Ibn Yunus (m. 958). A continuación analiza la posibilidad de que el nombre del referido personaje sea Ayyash Ibn Uŷayl Al-Himyari, apoyándose en Abu Abd Allah Muhammad Ibn Ali Al-Suri Al-Hafiz (m. 1057)4, en Al-Daraqutni (m. 995) y en Muawiya Ibn Hudayŷ (m. después 672), añadiendo que pertenecía a la tribu Ruayni. Y concluye indicando que Yaqub Ibn Sufyan (Al-Fasawi) (m. 890) en la Historia planteaba que en el año 100 vino Abbas Ibn Uŷayl de Al-Andalus a Ifriqiya ${ }^{5}$. Noticias que recoge en su totalidad y prácticamente en los mismos términos Al-Dabbi ${ }^{6}$. Ahora bien, este mismo autor, en un texto anterior, señala que Abbas Ibn Uŷayl entró en Al-Andalus como conquistador, y vino desde allí en barcos a Ifriqiya, lo que fue mencionado por Yaqub Ibn Sufyan (Al-Fasawi) ${ }^{7}$. Y en cuanto a Ibn Abd Al-Malik Al-Marrakushi pone de manifiesto que de Ayyash Ibn Uŷayl Al-Ruayni tenemos noticias gracias a Said Ibn Al-Musayyab y a Muawiya Ibn Hudayŷ; que era jefe de la policía (sahib al-shurta) de Muza Ibn Nusayr y le acompañó a Al-Andalus; y que fue valí del mar en la época de los Omeyas y vino en barcos de Al-Andalus a Ifriqiya en el año $100^{8}$.

${ }^{2}$ P. Guichard, L'integration des Baleares, pp. 56-57.

${ }^{3}$ J. Lirola Delgado, Conquistas, pp. 27 y 36.

${ }^{4}$ Cf. F. Sezgin, Geschichte, vol. I, cap. II-B, núm. 340, p. 233.

${ }^{5}$ Al-Humaydi, m. 1095 (I. Al-Abyari, Ŷadwat, vol. II, núm. 742, pp. 511-512).

${ }^{6}$ Al-Dabbi, m. 1203 (I. Al-Abyari, Bugyat, vol. II, núm. 1257, pp. 564-565).

${ }^{7}$ Al-Dabbi (I. Al-Abyari, Bugyat, vol. II, núm. 1247, p. 560).

${ }^{8}$ Ibn Abd Al-Malik Al-Marrakushi, m. 1303-1304 (M. Ibn Sharifa (ed.), Al-Dayl, vol. VIII-1, núm. 37, p. 244). 


\section{AYYASH IBN AJYAL}

Y, por lo demás, todo parece indicar que el personaje al que se refieren tales autores musulmanes, con variantes en cuanto al nombre, es el mismo y coincide también con el que citan el Seudo Ibn Qutayba e Ibn Idari como el personaje que estaba al mando de la flota musulmana de Ifriqiya en la expedición contra la isla de Sicilia en el año 86 de la Hégira ( 2 de enero a 22 de diciembre de 705 ). El primero de ellos expresa que Muza encargó los barcos del pueblo de Ifriqiya a Ayyash Ibn Ajyal, y éste pasó el invierno en el mar, y que llegó a una ciudad denominada Siracusa, regresando en el año $86^{9}$. Y el segundo manifiesta que Ibn Al-Qattan hace notar que se dijo que Muza, tras haber expresado su fidelidad a Al-Walid después de su envestidura, en ese mismo año (86 de la Hégira), envió a Zara Ibn Abi Mudrik a las tribus bereberes para cobrar sus tributos, y que después le encargó los barcos africanos a Ayyash Ibn Ajyal, el cual, navegando a Sicilia, llegó a una ciudad que se llama Siracusa, que conquistó con todo lo que contenía, y volviendo sano y salvo ${ }^{10}$.

Aunque en el segundo texto citado de Al-Dabbi se especifica que la llegada a Al-Andalus del personaje fue como conquistador ${ }^{11}$, sin embargo resulta muy clarificador el hecho de que Ibn Abd Al-Malik Al-Marrakushi diga que acompañó a Muza a Al-Andalus ${ }^{12}$. Con tal precisión resulta obvio que el referido almirante musulmán hubo de llegar a la península Ibérica en el año 93 de la Hégira (19 de octubre de 711 a 6 de octubre de 712), por lo que parece forzoso considerar que no participó en la invasión del 711.

\section{EXPEDICIÓN MARÍTIMA A CERDEÑA}

En efecto, como ya hemos manifestado en un anterior trabajo ${ }^{13}$, en el preciso momento de la invasión de la península Ibérica, llevada a cabo por Tariq, la flota de Ifriqiya se encontraba ocupada en una expedición contra la isla de Cerdeña, tal como expresan Yaqut Al-Rumi, Ibn Al-Atir, Al-Nuwayri e Ibn Tagribirdi. Estos autores musulmanes se muestran unánimes en manifiestar que Muza, en el año 92 de la Hégira (29 de octubre de 710 a 18 de octubre de 711), envió una expedición dirigida contra Cerdeña ${ }^{14}$. Para nosotros no cabe ninguna duda al respecto, y, si alguna se ha suscita-

\footnotetext{
9 Seudo Ibn Qutayba, hacia 861 (P. de Gayangos, The History, vol. I, Appendix E, p. LXVII). Resulta muy interesante que en el Seudo Ibn Qutayba aparezca Ayyash Ibn Ajyal formando parte de la expedición de Muza y también se manifieste, como en Ibn Abd Al-Malik al-Marrakushi, que era jefe de la policía (sahib alshurta) de éste (P. de Gayangos, The History, vol. I, Appendix E, p. LXXVI; J. Ribera, Historia de la conquista de España, p. 116), lo que claramente denota que en ambos se trataba de la misma persona.

${ }^{10}$ Ibn Al-Qattan, m. 1230, en Ibn Idari, m. después 1313 (E. Fagnan, Histoire de l'Afrique et de l'Espagne, vol. I, p. 35; M. Amari, Biblioteca arabo-sicula, vol. II, p. 3).

${ }_{11}$ Al-Dabbi (I. Al-Abyari, Bugyat, vol. II, núm. 1247, p. 560).

${ }_{12}$ Ibn Abd Al-Malik Al-Marrakushi (M. Ibn Sharifa, Al-Dayl, vol. VIII-1, núm. 37, p. 244).

$13 \mathrm{~J}$. Montenegro, A. del Castillo, Le règne de Rodéric, p. 13.

14 Yaqut Al-Rumi, m. 1229 (M. Amari, Biblioteca arabo-sicula, vol. I, p. 193: "Sardânîah (la Sadegna) (...) I Musulmani l'assalirono già e se ne insignorirono l'anno novantadue (...) sotto gli auspici (cf. n. 4: con l'esercito) di Mûsâ ibn Nusayr"); Ibn Al-Atir, m. 1233 (Ibidem, vol. I, pp. 356357: "Anno 92 (...) Quando Mûsâ (ibn Nusayr) conquistò la Spagna, ei mandò per mare un banda dell' esercito contro quest' isola. l'anno novantadue"); Al-Nuwayri, m. 1332 (M. Gaspar Remiro, Historia de los musulmanes, vol. II, p. 33: "Cuando Mûsâ entró en España, envió una división de su ejército a la isla de Cerdeña (...) La invadieron los musulmanes enviados en el año 92 de la Hégira”);
} 
do, ello se debe fundamentalmente a una traducción errónea del texto de Ibn Al-Atir llevado a cabo por Edmond Fagnan ${ }^{15}$ (que acepta Pierre Guichard en el sentido de que no excluye, e incluso sugiere, que los barcos enviados a Cerdeña habían podido efectuar esa expedición después de haber desembarcado las tropas en la península Ibérica $^{16}$ ), así como del texto de Al-Nuwayri, obra de William Mac Guckin de Slane ${ }^{17}$, que plantea una situación parecida.

Ciertamente, a nuestro entender, en lo que hace referencia al texto de Ibn Al-Atir, la traducción del original que se ajusta a lo correcto se corresponde con la que efectuó Michele Amari, quien interpreta que cuando (en el momento en que) Muza conquistó el territorio de Al-Andalus envió por mar en dirección a esta isla (de Cerdeña) una parte de su ejército, que el año 92 entró en ella ${ }^{18}$. Y por lo que atañe a Al-Nuwayri, consideramos que la traducción que se ajusta a lo correcto es la que llevó a cabo Mariano Gaspar Remiro, en el sentido de que cuando (en el momento en que) Muza entró en tierra de Al-Andalus marchó un grupo (una parte) de su ejército a la isla de Cerdeña y entró en ella en el año $92^{19}$.

Habida cuenta de que en todos los casos se alude al año 92 de la Hégira, resulta evidente que en estos textos se hace referencia a la invasión de Tariq por orden de Muza, a la sazón valí de Ifriqiya. Pero asimismo resulta muy claro que el envío de la flota a la isla de Cerdeña no tuvo lugar después de la invasión de la península Ibérica en el 711, pues lo que indican los textos es que ello sucedió en el momento en que las tropas musulmanas entraron en la península Ibérica. Así pues, parece forzoso que la flota musulmana de Ifrqiya no pudo ser utilizada para la invasión de la península Ibérica en el año 92 de la Hégira.

Por lo que atañe al relato que nos ha transmitido Ibn Abd Al-Hakam ${ }^{20}$, consideramos que podría igualmente hacer referencia a una expedición contra la isla de Cerdeña, pero no podemos compartir la hipótesis de Albert Gateau, según la cual se trataría de una flota enviada a Cerdeña desde la península Ibérica ${ }^{21}$. Parece posible que en Ibn Abd Al-Hakam existan dos referencias a expediciones a Cerdeña ${ }^{22}$, a saber, una relativa a la que acabamos de referir y la que aparece seguidamente en el texto, y que se centra en una expedición dirigida por Ata Ibn Rafi $^{23}$, la cual es sin duda la que aparece recogida en el texto del Seudo Ibn Qutayba, quien dice que en el año 84 de la Hégira (24 de enero de 703 a 13 de enero de 704) dicho personaje llegó a Ifri-

Ibn Tagribirdi, m. 1470 (M. Amari, Biblioteca arabo-sicula, vol. II, p. 704: “Anno 92 (...) Quest'anno fu conquistata l'isola di Sardegna dall'esercito di Mûsâ ibn Nusayr"; E. Fagnan, En-Nodjoum ezZâhira, p. 279: "En 92 (...) l'Espagne fut conquise par Târik ben Ziyâd, client de Moûsa ben Noçayr. En la même année l'île de Sardaigne fut conquise par des troupes de Moûsa ben Noçayr").

${ }_{15}$ Ibn Al-Atir (E. Fagnan, Ibn El-Athir, p. 51 = idem, Annales, p. 21: "En 92(...), Moûsa, qui venait de conquérir l'Espagne, fit embarquer une portion de ses troupes à destination de cette île").

${ }^{16}$ P. Guichard, L'integration des Baleares, p. 57. cf. A. Guillou, La lunga etè bizantina, p. 333.

${ }^{17}$ Al-Nuwayri (W. Mac Guckin de Slane, Histoire de la province d'Afrique, pp. 575-576: “Après son entrée en Espagne, dit le historien, Mousa envoya un détachement de troupes contre cette île (...) Elles y arrivèrent en l'an 92").

${ }_{18}$ Ibn Al-Atir (C.J. Tornberg, Ibn-El-Athiri chronicon, vol. IV, p. 449).

${ }_{19}$ Al-Nuwayri (M. Gaspar Remiro, Historia de los musulmanes, vol. II, p. 30, texto árabe).

${ }^{20}$ Ibn Abd Al-Hakam, m. 871 (E. Lafuente y Alcántara, Ajbar Machmuâ, pp. 212-213; A. Gateau, Ibn Abd al-Hakam, pp. 99 y 101 = idem, La conquête, pp. 251-252).

${ }^{21}$ A. Gateau, Ibn Abd Al-Hakam et les sources arabes, p.87.

22 A.M. Fahmy, Muslim Sea-Power, pp. 120-121. Cf. P. Sebag, Les expéditions, p. 75 y n. 14 (cf. también pp. 77-78).

${ }^{23}$ Ibn Abd Al-Hakam (E. Lafuente y Alcántara, Ajbar Machmuâ, p. 213; A. Gateau, Ibn Abd alHakam, p. 103 = idem, La conquête, pp. 252-253). 
qiya y con órdenes de realizar un desembarco en Cerdeña, hecho que llevó a cabo ${ }^{24}$. Respecto a esta empresa existe una interesante referencia en el papiro Aphrodito 1350 del British Museum ${ }^{25}$ : se trata de una carta, fechada en el cuarto día del mes Mecheir de la octava Indicción, esto es el 29 de enero de $710^{26}$, en la que Qurra Ibn Sharik AlAbsi, valí de Egipto, pedía a Basilio, administrador local del distrito de Aphrodito ${ }^{27}$, que en el momento que recibiese la carta le enviase información sobre los marineros que participaron en la expedición de la flota de Africa con Ata Ibn Rafi, enviada por Muza, a saber, el número de los que regresaron a Aphrodito, el número de los que se quedaron en Africa y la razón de que se quedaran allí, y el número de los que murieron allí o en su regreso a casa; el décimo quinto día del mismo mes, esto es el 9 de febrero, le fue enviada la información requerida, que fue llevada al valí por el mensajero Said. De manera que este papiro verifica la expedición marítima referida, que naturalmente tuvo que llevarse a cabo con anterioridad a la fecha en que la carta fue enviada.

\section{LA INVASIÓN DE LA PENÍNSULA IBÉRICA}

Por otra parte, no podemos olvidar que la mayoría de las fuentes musulmanas especifican que el paso de las tropas para la invasión de la península Ibérica en el 711 se realizó en barcos puestos a disposición por don Julián ${ }^{28}$, y lo mismo indican tanto Rodrigo Ximénez de Rada como la Crónica General de Alfonso X el Sabio ${ }^{29}$. Ciertamente existen otras fuentes que ofrecen algunas variantes al respecto: el Seudo Ibn Qutayba dice que fueron utilizados siete barcos encontrados por Tariq ${ }^{30}$; los Ajbar Maŷmua que cuatro barcos que tenían ${ }^{31}$; la Historia Pseudo-Isidoriana, el Fath AlAndalus y el manuscrito de Kairuán refieren solamente que don Julián pasó al mismo

\footnotetext{
${ }^{24}$ Seudo Ibn Qutayba (P. de Gayangos, The History, vol. I, Appendix E, p. LXVI; M. Amari, Biblioteca arabo-sicula, vol. I, pp. 273-275). Este último autor, en Storia dei musulmani, p. 293, fecha la expedición hacia el otoño de 703.

${ }^{25}$ H.I. Bell, Greek Papyri in the British Museum, vol. IV, pp. 24-25; H.I. Bell, Translations, p. 279; P. Sebag, Les expeditions, pp. 81-82; A.M. Fahmy, Muslim Sea-Power, pp. 120-121.

${ }^{26}$ En la obtención de la fecha hemos seguido, en general, los parámetros especificados en: R.S. Bagnall, K.A. Worp, The Chronological, pp.67-102 (v. esp. la nota en p. 94); C.R. Cheney, A Handbook, pp. 2-4.

${ }^{27}$ Sobre ambos personajes y sus cargos, $c f$. H.I. Bell, The Aphrodito, esp. pp. 99-101 y 106-107.

${ }^{28}$ Al-Waqidi, m. 823, en Al-Baladuri, m. 892 (Ph.K. Hitti, The Origins, vol. I, p. 365); Ibn Abd Al-Hakam (E. Lafuente y Alcántara, Ajbar Machmuâ, pp. 209-210; A. Gateau, Ibn Abd Al-Hakam, p. 91 = idem, La conquête, p. 248); Ahmad Al-Razi, m. 955, tomado de Al-Waqidi, en Ibn Idari (E. Fagnan, Histoire de l'Afrique et de l'Espagne, vol. II, p. 9); Ahmad Al-Razi, en la Crónica de 1344, 86, 4 del ms. M y 199, 4 del ms. U (D. Catalán, M.S. de Andrés, Crónica de 1344, p. 122); Arib Ibn Said, m. 980, en Ibn Al-Shabbat, m. 1282 (E. de Santiago Simón, Un fragmento, p. 32); Al-Bakri, m. 1094 (W. Mac Guckin de Slane, Description, p. 204); Ibn Al-Kardabus, de la segunda mitad del siglo XII (F. Maíllo, Ibn al-Kardabus, pp. 59-60); Al-Himyari, del siglo XV, pero su obra se basa en otra análoga del XIV (E. Lévi-Provençal, La péninsule Ibérique, p. 13); Al-Qalqashandi, m. 1418 (L. Seco de Lucena, Al-Qalqashandi, p. 56); Al-Maqqari, m. 1631 (P. de Gayangos, The History, vol. I, p. 266; E. Lafuente y Alcántara, Ajbar Machmuâ, p. 175).

${ }^{29}$ Rodrigo Ximénez de Rada, de rebus Hispaniae, 3, 20, terminada en 1243 (F.A. de Lorenzana, Rodericus, p. 66; A. Schott, Hispaniae illustratae, vol. II, p. 64); Crónica General de Alfonso X el Sabio, 556, del último cuarto del siglo XIII (R. Menéndez Pidal, Primera Crónica, vol. I, p. 309).

${ }^{30}$ Seudo Ibn Qutayba (P. de Gayangos, The History, vol. I, Appendix E, p. LXX; J. Ribera, Historia de la conquista de España, p. 105); Seudo Ibn Qutayba, en Ibn Al-Shabbat (E. de Santiago Simón, Un fragmento, p. 66).

${ }^{31}$ Ajbar Маŷmua (E. Lafuente y Alcántara, Ajbar Machmuâ, p. 21).
} 
tiempo que Tariq ${ }^{32}$; y el Dikr Bilad Al-Andalus que Tariq mandó construir los barcos ${ }^{33}$. Pero, en ningún caso, hacen referencia al uso de la flota musulmana de Ifriqiya. Por lo demás, no nos convence la opinión de Abdulwahid Dhanun Taha, quien sostiene que Tariq tenía barcos en Tánger, pero que quería navegar clandestinamente utilizando barcos mercantes desde Ceuta, puesto que ello hizo el paso mucho más lento y además se realizó de noche, con lo que hubiera dado igual ${ }^{34}$. De manera que las fuentes no permiten afirmar, más bien al contrario, que Tariq utilizó la flota musulmana de Ifriqiya para la invasión.

¿Pudo llegar la flota de Ifriqiya en el momento en que Muza se trasladó a la península Ibérica? Archibald Ross Lewis ha puesto de manifiesto que para inmovilizar las amenazas navales bizantinas a su espalda, Muza utilizaba la flota, encargada de guardar las comunicaciones norteafricanas y de vigilar a los bizantinos de Sicilia y Cerdeña ${ }^{35}$. Puesto que Muza no podía permitirse llevar consigo la flota, ocupada, como estaba, en otras empresas, encargó a su hijo Abd Allah el gobierno de Ifriqiya y marchó con su ejército hasta llegar al estrecho de Gibraltar desde donde cruzó hasta la península Ibérica ${ }^{36}$, en otros barcos. En efecto, tanto los Ajbar Maŷmua como Al-Maqqari indican que, después de la partida de Tariq, Muza había mandado construir barcos, y los tenía en gran número, en la orilla africana, y en ellos le envió los refuerzos que le solicitó $^{37}$. También en estos mismos barcos hubo de pasar Muza a la península Ibérica ${ }^{38}$. Y, por lo demás, Ibn Idari dice que, en el año 95 de la Hégira (26 de septiembre de 713 a 15 de septiembre de 714), Muza salió de la península Ibérica para regresar a Ifriqiya llevándose el botín con el que Dios le había gratificado, transportando en barcos todos los ricos despojos que formaban el oro, la plata y las pedrerías hasta Tánger, y después fueron cargados en carros $^{39}$. Muza había llegado en abril-mayo o en junio-julio del 712

32 Historia Pseudo-Isidoriana, 19, escrita por un mozárabe en Toledo muy probablemente a finales del siglo XI (Monumenta, vol. XI, p. 387; para una crítica a las tesis recientes que colocan la redacción en el siglo XII o principios del XIII, $c f$. J. Montenegro, A. del Castillo, Victoris Tunnunensis Chronicon, pp. 1060-1062); Fath Al-Andalus, escrito a finales del siglo XI o principios del XII (J. de González, Fatho-l-Andaluçi, p. 6; M.T. Penelas, La conquista, p. 10); manuscrito de Kairuán, f. 30r, escrito a finales del siglo XIII o comienzos del XIV (G. Levi della Vida, Note, pp. 162 y 191).

${ }_{33}$ Dikr Bilad Al-Andalus, 84, obra seguramente de la segunda mitad del siglo XIV o del XV (L. Molina, Una descripción anónima, p. 106).

${ }^{34}$ A.D. Taha, The Muslim Conquest, pp. 86-87.

${ }^{35}$ A.R. Lewis, Naval Power and Trade, p. 65. Ultimamente, P. Guichard, De la expansión árabe, p. 27, ha considerado la posibilidad de que la flota de Ifriqiya participó en las operaciones de la península Ibérica, posiblemente después de haber transportado a Muza.

36 Seudo Ibn Qutayba (P. de Gayangos, The History, vol. I, Appendix E, p. LXXI; J. Ribera, Historia de la conquista de España, p. 108); Ahmad Al-Razi, tomado de Al-Waqidi, en Ibn Idari (E. Fagnan, Histoire de l'Afrique et de l'Espagne, vol. II, p. 20); Ahmad Al-Razi, en Ibn Abi AlFayyad, m. 1066 (M.M. Antuña, Traducción de un pasaje, p. 354); Ahmad Al-Razi, en la Crónica de 1344, 93, 3 del ms. M y 206, 3 del ms. U (D. Catalán, M.S. de Andrés, Crónica de 1344, p. 143); Arib Ibn Said, en Ibn Al-Shabbat (E. de Santiago Simón, Un fragmento, p. 50); Dikr Bilad Al-Andalus, 85-86 (L. Molina, Una descripción anónima, vol. II, p. 108); Ibn Tagribirdi (E. Fagnan, En-Nodjoum ez-Zâhira, p. 279); Al-Maqqari, m. 1631 (P. de Gayangos, The History, vol. I, p. 283; E. Lafuente y Alcántara, Ajbar Machmuâ, p. 187); Ibn Abi Dinar, su obra debió de ser escrita en 1681 o en 1698 (E. Pellissier de Reynaud, J.P.A. Rémusat, Exploration scientifique, vol. VII, p. 59).

${ }^{37}$ Ajbar Maŷmua, redactados posiblemente a finales del siglo X o principios del XI (E. Lafuente y Alcántara, Ajbar Machmuâ, p. 21); Al-Maqqari (P. de Gayangos, The History, vol. I, p. 270; E. Lafuente y Alcántara, Ajbar Machmuâ, p. 177).

${ }^{38}$ Cf. A.R. Lewis, Naval Power and Trade, p. 65.

${ }^{39}$ Ibn Idari (E. Fagnan, Histoire de l'Afrique et de l'Espagne, vol. I, p. 37). Cf. Ibn Habib, m. 853 (M.M. Antuña, Notas, pp. 261-262): se trata del ms. de la Bodleian de Oxford atribuido erróneamente 
y partió tal vez en el verano del 714, después de una estancia de dos años y algunos meses ${ }^{40}$. Desde luego, parece seguro que Muza hubo de abandonar la península Ibérica en el año 714, puesto que, tal como hemos puesto de manifiesto ${ }^{41}$, Abu Nasr, el segundo de los emisarios enviados por el califa Al-Walid, le encontró en Lugo. Y este emisario había desembarcado a principios del año 95 de la Hégira, según refieren Ahmad AlRazi $^{42}$, Al-Gassani ${ }^{43}$ y el Fath Al-Andalus ${ }^{44}$. A tenor de lo que especifican Al-Humaydi, Al-Dabbi e Ibn Abd Al-Malik Al-Marrakushi, hemos de considerar que los barcos volvieron otra vez y se mantuvieron en la península Ibérica -no se puede olvidar que algunos autores musulmanes ponen de manifiesto que Muza quería convertir a Sevilla en base naval de los musulmanes ${ }^{45}$ - hasta el año 100 . Tal vez como consecuencia de que el nuevo valí, Al-Samh Ibn Malik Al-Jawlani, fue nombrado directamente por el califa Umar II, con jurisdicción específica para Al-Andalus e independiente del gobierno de Ifriqiya, hecho en el que coinciden las fuentes musulmanas.

En suma, de las fuentes disponibles no es posible deducir que en ningún momento se utilizara la flota de Ifriqiya para la invasión musulmana de la península Ibérica. El tema no es baladí, puesto que ello ayuda a comprender las circunstancias en las que tuvo lugar la misma.

\section{ASPECTOS DE LA DESAPARICIÓN DEL REINO VISIGODO DE TOLEDO}

Hemos puesto de manifiesto en un trabajo anterior que resultan incontrovertibles toda una serie de aspectos que tienen que ver con la desaparición del reino visigodo de Toledo como consecuencia de la invasión musulmana ${ }^{46}$.

a Ibn Abi Riqa, primera mitad del siglo IX, por R.P.A. Dozy, seguido, entre otros muchos, por C. Sánchez-Albornoz, pero que J. Aguadé, Abd alMalik b. Habib, pp. 77-88, considera que es de Ibn Habib y que nos ha llegado en una redacción, con breves interpolaciones, de su discípulo Al-Magami, quien debió realizarla entre los años 888 y 901; cf. A. Christys, How the Royal House, p. 238; Ibn Habib, en Al-Gassani, embajador marroquí en la Corte de Carlos II (J. Ribera, Historia de la conquista de Espa$\tilde{n} a$, pp. 181-182; Alfredo Bustani, El viaje del visir, p. 112); Seudo Ibn Qutayba (P. de Gayangos, The History, vol. I, Appendix E, p. LXIX; J. Ribera, Historia de la conquista de España, p. 122); Ibn Abd Al-Hakam (E. Lafuente y Alcántara, Ajbar Machmuâ, p. 214; A. Gateau, Ibn Abd al-Hakam, p. 105 = idem, La conquête, p. 253); Ibn Al-Kardabus (F. Maíllo, Ibn al-Kardabus, p. 68); Al-Maqqari (P. de Gayangos, The History, vol. I, p. 292; E. Lafuente y Alcántara, Ajbar Machmuâ, p. 189).

40 C. Sánchez-Albornoz, ¿Muza en Asturias?, pp. 464-470; idem, Itinerario de la conquista, p. 63 n. 76. Así aparece igualmente reflejado en publicaciones recientes como, por ejemplo: J.M. Abun-Nasr, A history, p. 71; A.D. Taha, The Muslim Conquest, pp. 94 y 100; P. Chalmeta, Invasión e islamización, pp. 169, 172 y 198.

${ }^{41}$ J. Montenegro, A. del Castillo, Le règne de Rodéric, p. 4. Cf. idem, La expedición, p. 195 y n. 3841; idem, La campaña de Muza, pp. 16-17.

${ }^{42}$ Ahmad Al-Razi, tomado de Ibn Habib, en Al-Gassani (J. Ribera, Historia de la conquista de España, p. 176; A. Bustani, El viaje del visir, p. 107).

${ }^{43}$ Al-Gassani (J. Ribera, Historia de la conquista de España, p. 180; A. Bustani, El viaje del visir, p. 110).

${ }^{44}$ Fath Al-Andalus (J. de González, Fatho-l-Andaluçi, pp. 16 y 19; M.T. Penelas, La conquista, pp. 22 y 26).

${ }^{45}$ Ajbar Maŷmua (E. Lafuente y Alcántara, Ajbar Machmuâ, p. 31). De hecho, el Fath Al-Andalus (J. de González, Fatho-l-Andaluçi, p. 19; M.T. Penelas, La conquista, p. 26), Al-Maqqari (P. de Gayangos, The History, vol. I, p. 292; E. Lafuente y Alcántara, Ajbar Machmuâ, p. 193) y Al-Gassani (J. Ribera, Historia de la conquista de España, p. 181; A. Bustani, El viaje del visir, p. 111), con referencia al año 95 de la Hégira, dicen que Muza, al llegar a Sevilla, se embarcó con los que deseaban regresar.

${ }^{46} \mathrm{~J}$. Montenegro, A. del Castillo, Le règne de Rodéric, pp. 11-17. 
La elección de Rodrigo como rey, un personaje con notable experiencia en el terreno militar, no pudo ser casual justo en el momento en que el reino visigodo de Toledo necesitaba alguien de tales características para intentar frenar lo que ya parecía más que previsible, a saber, la posibilidad de que, en breve plazo, los musulmanes pretendieran invadir la península Ibérica, como de hecho ocurrió con la llegada de Tariq.

Aunque no se puede poner en duda que la expansión musulmana en el Norte de Africa fue decisiva en la invasión de la península Ibérica, lo cierto es que tal acontecimiento sólo tomó carta de naturaleza a partir de principios de noviembre del 709, es decir, en el momento en que se llevó a efecto el pacto con el denominado conde don Julián, que es cuando de alguna forma los musulmanes tuvieron clara conciencia de que la conquista podría resultar sumamente fácil, habida cuenta de la debilidad de la monarquía visigoda ${ }^{47}$. Y seguramente serían también conscientes entonces de la posibilidad de ayuda interna a los invasores. Es eso precisamente lo que denotan con nitidez las fuentes cristianas, esto es, que la caída del reino visigodo de Toledo fue posible gracias al apoyo del que gozaron los invasores dentro del propio reino. La traición de los witizanos parece ponerse de manifiesto en un texto del Anónimo Mozárabe de $754^{48}$, pero resulta más clara en otro, en el que se hace referencia a Oppa, hijo de Egica ${ }^{49}$. Y otras fuentes señalan asimismo con nitidez que esta traición fue definitiva a la hora de explicar el rápido triunfo de la invasión musulmana ${ }^{50}$. En las crónicas del ciclo de Alfonso III solamente un texto de la versión Ovetense de la Crónica de Alfonso III hace alusión a que los sarracenos fueron llamados, pues los hijos de Witiza habían enviado emisarios a África pidiéndoles ayuda, de forma que, una vez trasladados en barcos, los introdujeron en la península Ibérica ${ }^{51}$. Semejante versión de los acontecimientos aparece ya anteriormente en Isa Ibn Muhammad, un autor de la primera mitad del siglo IX, quien presenta a los mismos hijos de Witiza como los emisarios ${ }^{52}$, lo que aparece claramente en ciertas fuentes cristianas tardías

${ }^{47}$ Cf. A. Barbero, M. Vigil, La formación, p. 205 y n. 15; A.D. Taha, The Muslim Conquest, p. 85.

48 Continuatio Hispana, 68 (Monumenta, vol. XI, p. 352).

49 Continuatio Hispana, 70 (Monumenta, vol. XI, p. 353).

${ }^{50}$ La Crónica Albeldense, 14, 34 y 17, 1, de finales del siglo IX (J. Gil Fernández, J.L. Moralejo, J.I. Ruiz de la Peña, Crónicas asturianas, pp. 171 y 182-183; la Crónica de Alfonso III, 7 y 8 (Rotense y Ovetense), de finales del siglo IX (J. Gil Fernández, et al., Crónicas asturianas, pp. 120 y 123; y pp. 123-124); la Historia Pseudo-Isidoriana, 20 (Monumenta, vol. XI, pp. 387-388); otros textos que aparecen en algunos códices: Additamenta ad Chronica Maiora, ex codice Londiniensi n.12024 saec.XI. inter excerpta ex Beda (Monumenta, vol. XI, p. 493) y Additamenta ad Chronica Minora, ex variis libris. sub Anastasio II (a. 713-716) (Monumenta, vol. XI, p. 505); la Historia Silense, datada en las primeras décadas del siglo XII (F. Santos Coco, Historia Silense, pp. 14-15); la Crónica Najerense, 1, 14, de la segunda mitad del siglo XII (A. Ubieto Arteta, Crónica Najerense, pp. 43-44); Lucas de Tuy, 3, 64-66, su Chronicon mundi se terminó en 1236 (J. Puyol, Crónica de España, pp. 267-269; A. Schott, Hispaniae illustratae, vol. IV, p. 70); Rodrigo Ximénez de Rada, de rebus Hispaniae, 3, 20 (F.A. de Lorenzana, Rodericus, pp. 66-67; A. Schott, Hispaniae illustratae, vol. II, p. 64); y la Crónica General de Alfonso X el Sabio, 557 (R. Menéndez Pidal, Primera Crónica, vol. I, pp. 309-310). Cf. J. Montenegro, A. del Castillo, Don Pelayo y los orígenes, p. 8 n. 6; idem, Análisis crítico, esp. pp. 405-409. La traición de los witizanos es supuesta por A. Christys, How the Royal House, pp. 233-234 (cf. pp. 238-239) como una leyenda sin valor explicativo; $c f$. R. Collins, La conquista, pp. 37 y 133.

${ }^{51}$ Crónica de Alfonso III, 6 (J. Gil Fernández et al., Crónicas asturianas, p. 121).

${ }_{52}$ Isa Ibn Muhammad, en Ibn Idari (E. Fagnan, Histoire de l'Afrique et de l'Espagne, vol. II, pp. 9-10). Cf. Al-Raqiq, m. después 1027 (J. Vallvé, Nuevas ideas, p. 138). 
como la Historia Silense ${ }^{53}$, la Crónica Najerense ${ }^{54}$, Lucas de Tuy ${ }^{55}$, Rodrigo Ximénez de Rada $^{56}$ y la Crónica General de Alfonso X el Sabio ${ }^{57}$.

No puede ser casual que, cuando se produjo el desembarco de Tariq, don Rodrigo se hallase en la zona norte peninsular combatiendo a los vascones, como indican algunas fuentes musulmanas ${ }^{58}$. Ello permite suponer que los musulmanes disponían de una información precisa, que sólo podía haber sido suministrada por una facción contraria al monarca visigodo. Pedro Chalmeta considera posible que el conde don Julián, que estaba bien enterado de los acontecimientos en la península Ibérica, indicara a Tariq la oportunidad que suponía el hecho de que Rodrigo se encontrase luchando contra los vascones ${ }^{59}$. Ahora bien, tal hipótesis solo sería verosímil si se pudiese aceptar la tesis desarrollada por Luis Agustín García Moreno, en el sentido de que el conde don Julián sería el comandante bizantino de Ceuta, quien poniéndose al servicio del rey Witiza habría ostentado el cargo visigodo de conde del territorio de Julia Traducta (Algeciras) junto con Ceuta ${ }^{60}$, pues en tal supuesto hubiera tenido una buena información sobre el reino visigodo de Toledo. Sin embargo, ya pusimos de manifiesto en trabajos anteriores ${ }^{61}$ que la referencia de las fuentes musulmanas a un gobierno de don Julián en Algeciras resulta ser un claro error, ya sea como mantiene Juan Menéndez Pidal, como consecuencia de la existencia de diferentes lugares en el litoral de Africa y de España con los nombres de "La Isla" y "La Verde" (Algeciras deriva de Al-Ŷazira Al-Jadra que significa la Isla Verde), lo que pudo generar una confusión que llevó a suponer que don Julián controlaba un territorio en la penínsu-

\footnotetext{
${ }^{53}$ Historia Silense (F. Santos Coco, Historia Silense, pp. 14-15).

${ }^{54}$ Crónica Najerense, 1, 13 (A. Ubieto Arteta, Crónica Najerense, p. 43).

${ }_{55}$ Lucas de Tuy, 3, 64 (J. Puyol, Crónica de España, p. 266; A. Schott, Hispaniae illustratae, vol. IV, p. 70).
}

${ }_{56}$ Rodrigo Ximénez de Rada, de rebus Hispaniae, 3, 18 (F.A. de Lorenzana, Rodericus, p. 64; A. Schott, Hispaniae illustratae, vol. II, p. 63). p. 307).

57 Crónica General de Alfonso X el Sabio, 553 (R. Menéndez Pidal, Primera Crónica, vol. I,

58 Seudo Ibn Qutayba (P. de Gayangos, The History, vol. I, Appendix E, p. LXX; J. Ribera, Historia de la conquista de España, p. 106); Seudo Ibn Qutayba, en Ibn Al-Shabbat (E. de Santiago Simón, Un fragmento, p. 67); Ajbar Maŷmua (E. Lafuente y Alcántara, Ajbar Machmuâ, p. 21); Fath Al-Andalus (J. de González, Fatho-l-Andaluçi, p. 7; M.T. Penelas, La conquista, p. 12); Al-Maqqari (P. de Gayangos, The History, vol. I, p. 268; E. Lafuente y Alcántara, Ajbar Machmuâ, p. 176). Por lo demás, hay que denotar igualmente que tanto Ibn Al-Atir (E. Fagnan, Ibn El-Athir, p. 43 = idem, Annales, p. 13) como Al-Nuwayri (M. Gaspar Remiro, Historia de los musulmanes, vol. II, p. 28; W. Mac Guckin de Slane, Ibn Khaldoun, vol. I, pp. 347-348 = idem, Histoire de la province d'Afrique, p. 568) dicen simplemente que Rodrigo se encontraba ocupado en una expedición militar; $c f$. Ibn Jallikan, m. 1282 (W. Mac Guckin de Slane, Ibn Khallikan's, vol. III, p. 477); y asimismo, Ibn Habib (M.M. Antuña, Notas, p. 254).

${ }^{59}$ P. Chalmeta, Invasión e islamización, p. 133 (cf. asimismo, p. 148).

${ }^{60}$ L.A. García Moreno, Ceuta, pp. 1113-1114; idem, Las invasiones, p. 268 n. 111; idem, Los últimos tiempos, p. 438; idem, La talasocracia, p. 105; idem, El Africa bizantina, p. 191. Cf. H.V. Livermore, The Origins, pp. 264 y 281, quien considera que habida cuenta de que el término de comes Iulianus era un nombre génerico para designar al gobernador de la región de Iulia Traducta, mediante la cual las relaciones con Africa fueron sostenidas, los autores musulmanes otorgaron el nombre de Julián al gobernador o gobernadores que tanto Uqba Ibn Nafi Al-Fihri como Muza encontraron en Tánger y Ceuta, y que el comes Iulianus tras la conquista musulmana de la península Ibérica fue destituido de Ceuta y recompensado con territorios en España. n. $39-45$.

${ }^{61}$ J. Montenegro, A. del Castillo, Precisiones, p. 81; idem., Theodemir's Victory, pp. 409-410 y 
la Ibérica ${ }^{62}$, o como considera Claudio Sánchez-Albornoz, por tratarse de un suceso posterior a los que consignan la presencia de don Julián en Ceuta ${ }^{63}$, pues parece irrebatible lo apuntado por Eduardo Saavedra, en el sentido de que si don Julián hubiera gobernado en Algeciras, esta plaza no hubiera tenido que ser tomada por las armas como de hecho ocurrión ${ }^{4}$.

\section{LA INVASIÓN NO ESTABA PROGRAMADA}

En cualquier caso, todo parece indicar que el califato de Damasco no había planificado la invasión de la península Ibérica ${ }^{65}$. Se trató de una expedición, en barcos prestados, lo que constituye buena prueba de la improvisación de la aventura, que pudo terminar en desastre, y que, por el contrario, fue un éxito debido a la debilidad interna del reino visigodo de Toledo y a la colaboración activa de una facción de dicho reino: de hecho las fuentes musulmanas inciden claramente en la idea de que los musulmanes contaron con la inestimable ayuda de la facción witizana ${ }^{66}$. Que la invasión de la península Ibérica no había sido programada se pone de manifiesto en las reticencias de Al-Walid, quien exigió a Muza seguridades previas, habida cuenta de que se exponía a los musulmanes a la necesidad de tener que cruzar el mar, como denotan las propias fuentes musulmanas ${ }^{67}$. Y que los musulmanes no tenían un gran

62 J. Menéndez Pidal, Leyendas, p. 290 n. 2.

${ }^{63}$ C. SánchezAlbornoz, Frente, p. 297 n. 5.

${ }^{64}$ E. Saavedra, Estudio, p. 53.

${ }^{65}$ P. Chalmeta, Invasión e islamización, p. 121, dice que las fuentes musulmanas no dan, en absoluto, la sensación de estar describiendo una acción de envergadura, oficial, preparada y programada. Cf. R.P.A. Dozy, Recherches, vol. I, p. 71.

${ }^{66}$ Ahmad Al-Razi, en la Crónica de 1344, 202, 711 del ms. U (D. Catalán, M.S. de Andrés, Crónica de 1344, pp. 132-133); Ibn Al-Qutiyya, m. 977 (J. Ribera, Historia de la conquista de España, pp. 2-3); Arib Ibn Said, en Ibn Al-Shabbat (E. de Santiago Simón, Un fragmento, pp. 33-34); Ajbar Maŷmua (E. Lafuente y Alcántara, Ajbar Machmuâ, pp. 21-22); Fath Al-Andalus (J. de González, Fatho-l-Andaluçi, p. 7; M.T. Penelas, La conquista, p. 12); Ibn Al-Atir (E. Fagnan, Ibn El-Athir, p. 44 = idem, Annales, p. 14); Al-Himyari (E. Lévi-Provençal, La péninsule Ibérique, p. 14); Al-Nuwayri (M. Gaspar Remiro, Historia de los musulmanes, vol. II, p. 29; W. Mac Guckin de Slane, Ibn Khaldoun, vol. I, p. 348 = idem, Histoire de la province d'Afrique, p. 569); Al-Maqqari (P. de Gayangos, The History, vol. I, pp. 270-271 y vol, II, p. 14; E. Lafuente y Alcántara, Ajbar Machmuâ, pp. 178 y 184-185).

${ }^{67}$ Ahmad Al-Razi, en la Crónica de 1344, 85, 11 del ms. M y 198, 11 del ms.U (D. Catalán, M.S. de Andrés, Crónica de 1344, p. 119); Arib Ibn Said, en Ibn Idari (E. Fagnan, Histoire de l'Afrique et de l'Espagne, vol. II, p. 7); Ajbar Maŷmua (E. Lafuente y Alcántara, Ajbar Machmuâ, p. 20); Ibn AlKardabus (F. Maíllo, Ibn Al-Kardabus, p. 58); Ibn Al-Atir (E. Fagnan, Ibn El-Athir, pp. 41-42 = idem, Annales, pp. 11-12); Al-Himyari (E. Lévi-Provençal, La péninsule Ibérique, p. 12); Al-Nuwayri (M. Gaspar Remiro, Historia de los musulmanes, vol. II, p. 27; W. Mac Guckin de Slane, Ibn Khaldoun, vol. I, p. 346 = idem, Histoire de la province d'Afrique, p. 566); Al-Maqqari (P. de Gayangos, The History, vol. I, pp. 264-265; E. Lafuente y Alcántara, Ajbar Machmuâ, p. 174). Interesante la apreciación de Ishaq Ibn Al-Husayn, de finales del siglo X (A. Codazzi, Il compendio, pp. 455-456), el cual expone que Al-Walid se lo prohibió diciendo que la frontera de los musulmanes era el mar; e igualmente de Ishaq Ibn Al-Hasan (F. Castelló, El “Dikr al-Aqalim”, p. 254), aunque en este caso la razón de la prohibición del califa fue que se iba a precipitar al mar con los musulmanes; sobre la posible identidad de ambas obras, aunque la segunda es más completa, remitimos al trabajo de F. Castelló, pp. 19-21 y 30-35. Asimismo, Rodrigo Ximénez de Rada, de rebus Hispaniae, 3, 19 (F.A. de Lorenzana, Rodericus, p. 65; A. Schott, Hispaniae illustratae, vol. II, p. 63); y la Crónica General de Alfonso X el Sabio, 555 (R. Menéndez Pidal, Primera Crónica, vol. I, p. 308). En cambio, el Fath Al-Andalus (J. de González, Fatho-l-Andaluçi, p. 5; M.T. Penelas, La conquista, p. 9) cuenta 
interés en extenderse por la península Ibérica lo prueba el hecho de que Umar II, hacia abril del 719, fecha de la llegada del valí Al-Samh Ibn Malik Al-Jawlani, se planteó la evacuación de los musulmanes de la península Ibérica sobre la base del aislamiento en que se encontraban y la vecindad de los enemigos ${ }^{68}$.

\section{CONCLUSIÓN}

Así pues, la invasión del reino visigodo de Toledo fue desde luego producto del propio expansionismo musulmán, pero la posibilidad real y la facilidad con la que se llevó a cabo fue consecuencia del pacto con don Julián y de la ayuda de la facción witizana, y desde luego la no participación de la flota musulmana de Ifriqiya, como apuntan las fuentes, refuerza nuestra hipótesis acerca de la falta de premeditación en la empresa por parte de las autoridades musulmanas.

\section{BIBLIOGRAFÍA CITADA}

Abun-Nasr, Jamil Mir'i, A history of the Maghrib in the Islamic period, Cambridge, Cambridge University Press, 1987.

Aguadé, Jorge, Abd al-Malik b. Habib (m. 238/853). Kitab al-Ta'rij (La Historia), Madrid, Consejo Superior de Investigaciones Científicas, 1991.

Al-Abyari, Ibrahim (ed.), Ŷadwat Al-muqtabis fi Ta'rij ulama Al-Andalus, Beirut, Dar Al-Kitab Al-Lubnani, 1984.

Al-Abyari, Ibrahim (ed.), Bugyat Al-multamis fi Ta'rij riyal ahl Al-Andalus, El CairoBeirut, Dar Al-Kitab Al-Masri - Dar Al-Kitab Al-Lubnani, 1989.

Amari, Michele, Biblioteca arabo-sicula, Turín-Roma, Ermanno Loescher, 1880-1881. Amari, Michele, Storia dei musulmani di Sicilia, [2 ${ }^{\mathrm{a}}$ ed. modificada y aumentada], Catania, Romeo Prampolini, 1933.

Antuña, Melchor M., Notas de Ibn Abi Riqa de las lecciones de Ibn Habib acerca de la conquista de España por los árabes, "Cuadernos de Historia de España" 1-2 (1944), pp. 248-268.

Antuña, Melchor M., Traducción de un pasaje del Ibar de Aben Abí Alfayyad relativo a la Historia de la Conquista de España por los musulmanes y a los primeros valies de Al-Andalus, en Sánchez-Albornoz, Claudio, En torno a los orígenes del Feudalismo. Los árabes y el régimen prefeudal carolingio. Fuentes de la Historia hispano-musulmana del siglo VIII, reimp. Madrid, Istmo, 1993, vol. II, pp. 351-360.

Bagnall, Roger Shaler; Worp, Klaas Anthony, The Chronological Systems of Byzantine Egypt, Zutphen, Terra, 1978.

Barbero, Abilio; Vigil, Marcelo, La formación del feudalismo en la península Ibérica, Barcelona, Crítica, 1978.

que el califa le dijo que reuniese tropas, atravesase el mar y se apoderase de la península Ibérica, mientras que la idea de un miedo al mar lo pone en boca de Muza.

${ }^{68}$ Ahmad Al-Razi, en Al-Gassani (J. Ribera, Historia de la conquista de España, p. 177; A. Bustani, El viaje del visir, p. 108); Ibn Al-Qutiyya (J. Ribera, Historia de la conquista de España, p. 9); Ajbar Maŷmua (E. Lafuente y Alcántara, Ajbar Machmuâ, p. 34); Ibn Hayyan, m. 1076, en Al-Maqqari (P. de Gayangos, The History, vol. II, p. 32; E. Lafuente y Alcántara, Ajbar Machmuâ, p. 197); Ibn Al-Atir (E. Fagnan, Ibn El-Athir, p. 92 = idem, Annales, p. 214); Ibn Idari (E. Fagnan, Histoire de l'Afrique et de l'Espagne, vol. II, pp. 34-35). 
Bell, Harold Idris, The Aphrodito Papyri, "Journal of Hellenic Studies" 28 (1908), pp. 97-120.

Bell, Harold Idris, Translations of the Greek Aphrodito Papyri in the British Museum, "Der Islam" 2 (1911), pp. 269-283.

Bell, Harold Idris (ed.), Greek Papyri in the British Museum. The Aphrodito Papyri, with an Appendix of Coptic Papyri edited by Walter Ewing Crum, Londres, British Museum, 1910.

Bustani, Alfredo, El viaje del visir para la liberación de los cautivos, por el visir Abú Abdel-lah Mohamed ben Abdeluahab conocido por el visir El Gassani, El Andalusi, Tánger, Instituto General Franco, 1940.

Castelló, Francisco, El "Dikr al-Aqalim” de Ishaq ibn al-Hasan al-Zayyat (Tratado de Geografía Universal), Barcelona, Consejo Superior de Investigaciones Científicas, 1989.

Catalán, Diego; Andrés, María Soledad de, Crónica de 1344, Madrid, Gredos, 1970.

Chalmeta, Pedro, Invasión e islamización. La sumisión de Hispania y la formación de Al-Andalus, Madrid, Mapfre, 1994.

Cheney, Christopher Robert (ed.), A Handbook of Dates, [nueva ed. revisada por Michael Jones], Cambridge, Cambrigde University Press, 2000.

Christys, Ann, How the Royal House of Witiza Survived the Islamic Conquest of Spain, en Pohl, Walter; Diesenberger, Maximilian (eds.), Integration und Herrschaft. Ethnische Identitäten und soziale Organisation im Frühmittelalter, Viena, Österreichische Akademie der Wissenschaften, 2002, pp. 233-246.

Codazzi, Angela, Il compendio geografico arabo di Ishaq ibn al-Husayn, "Rendiconti della R. Accademia Nazionale dei Lincei. Classe di Scienze morali, storiche e filologiche", 5 (1929), pp. 373-463.

Collins, Roger, La conquista árabe, 710-797, Barcelona, Crítica, 1991.

Dozy, Reinhart Pieter Anne, Recherches sur l'histoire et la littérature de l'Espagne pendant le Moyen Age, reimp. Amsterdam, Oriental Press, 1965.

Fagnan, Edmond, Annales du Maghreb et de l'Espagne par Ibn El-Athir, "Revue Africaine" 41 (1897), pp. 5-33, 185-266 y 351-385.

Fagnan, Edmond, Ibn El-Athir. Annales du Maghreb et de l'Espagne, Argel, Adolphe Jourdan, 1901.

Fagnan, Edmond, Histoire de l'Afrique et de l'Espagne intitulée al-Bayano'l-Mogrib, Argel, Imp. Orientale, 1901-1904.

Fagnan, Edmond, En-Nodjoum ez-Zâhira. Extraits relatifs au Maghreb, "Recueil des notices et mémoires de la Société Archéologique du Département de Constantine" 40 (1906), pp. 269-382.

Fahmy, Aly Mohamed, Muslim Sea-Power in the Eastern Mediterranean. From the Seventh to the Tenth Century A.D., El Cairo, National Publication and Printing House, 1966.

García Moreno, Luis Agustín, Ceuta y el estrecho de Gibraltar durante la Antigüedad tardía (siglos V-VIII), en Actas del Congreso Internacional "El estrecho de Gibraltar". Ceuta, 1987, Madrid, Universidad Nacional de Educación a Distancia, 1988, vol. I, pp. 1095-1114.

García Moreno, Luis Agustín, Las invasiones, la ocupación de la Península y las etapas hacia la unificación territorial, en Historia de España de R. Menéndez Pidal, Madrid, Espasa Calpe, 1991, vol. III-1, pp. 59-278.

García Moreno, Luis Agustín, Los últimos tiempos del reino visigodo, "Boletín de la Real Academia de la Historia" 189 (1992), pp. 425-459.

García Moreno, Luis Agustín, La talasocracia protobizantina en el Occidente mediterráneo, en Bádenas, Pedro; Egea, José María (eds.), Oriente y Occidente

ANUARIO de Estudios MEdievales, 42/2, julio-diciembre 2012, pp. 755-769

ISSN 0066-5061, doi:10.3989/aem.2012.42.2.16 
en la Edad Media. Influjos bizantinos en la cultura occidental, Vitoria, Universidad del País Vasco, 1993, pp. 95-105.

García Moreno, Luis Agustín, El Africa bizantina y España (siglos VI y VII): intercambios políticos, "Quaderni Catanesi di Studi Antichi e Medievali" 1 (2002), pp. 123-192.

Gaspar Remiro, Mariano, Historia de los musulmanes de España y Africa por EnNuguairí, Granada, Centro de Estudios Históricos de Granada y su reino, 1917-1919.

Gateau, Albert, Ibn Abd al-Hakam. La conquête de l'Afrique du Nord et de l'Espagne, "Revue Tunisienne" 6/23-24 (1935), pp. 247-270.

Gateau, Albert, Ibn Abd Al-Hakam et les sources arabes relatives à la conquête de l'Afrique du Nord et de l'Espagne, "Revue Tunisienne" 8/29 (1937), pp. 61-88.

Gateau, Albert, Ibn Abd al-Hakam. Conquête de l'Afrique du Nord et de l'Espagne, $2^{a}$ ed., Argel, Carbonel, 1947.

Gayangos, Pascual de, The History of the Mohammedan Dynasties in Spain, Londres, The Oriental Translation Fund of Great Britain and Ireland, 1840-1843.

Gil Fernández, Juan; Moralejo, José Luis; Ruiz de la Peña, Juan Ignacio, Crónicas asturianas, Oviedo, Universidad de Oviedo, 1985.

González, Joaquín de, Fatho-l-Andaluçi. Historia de la conquista de España. Códice arábigo del siglo XII, Argel, Imp. de la Nueva Asociación Obrera León Remordet y Cia., 1889.

Guichard, Pierre, L'integration des Baleares au pouvoir omeyyade de Cordoue, en Rosselló-Bordoy, Guillem (ed.), Les illes orientals d'Al-Andalus i les seves relacions amb Sharq al-Andalus, Magrib i Europa cristiana (ss. VIII-XIII), Palma de Mallorca, Institut d'Estudis Baleàlics, 1987, pp. 55-71.

Guichard, Pierre, De la expansión árabe a la Reconquista: Esplendor y fragilidad de Al-Andalus, Granada, Fundación El Legado Andalusí, 2002.

Guillou, André, La lunga etè bizantina: politica ed economia, en Guidetti, Massimo (ed.), Storia dei sardi e della Sardegna, Milán, Jaca Book, 1988, vol. I, pp. 329-371.

Hitti, Philip Khûri, The Origins of the Islamic State, reimp. Nueva York, Ams Press, 1968.

Ibn Sharifa, Muhammad (ed.), Al-Dayl wa-l-takmila li-kitabay Al-Mawsul wa-l-Sila, Rabat, Academia del Reino de Marruecos, 1984.

Lafuente y Alcántara, Emilio, Ajbar Machmuâ (Colección de tradiciones). Crónica anónima del siglo XI, Madrid, Real Academia de la Historia, 1867.

Levi della Vida, Giorgio, Note di storia letteraria arabo-ispanica, Roma, Istituto per l'Oriente, 1971.

Lévi-Provençal, Évariste, La péninsule Ibérique au Moyen-Âge, Leiden, E.J. Brill, 1938.

Lewis, Archibald Ross, Naval Power and Trade in the Mediterranean A.D. 500-1100, Princeton, Princeton University Press, 1951.

Lirola Delgado, Jorge, Conquistas por mar, en Al-Andalus y el Mediterráneo, Barcelona, Lunwerg, 1995, pp. 27-36.

Livermore, Harold Victor, The Origins of Spain and Portugal, Londres, George Allen and Unwin, 1971.

Lorenzana, Francisco Antonio de, Rodericus Ximenius de Rada, Opera, reimp. Valencia, Anubar, 1968.

Mac Guckin de Slane, William, Histoire de la province d'Afrique et du Magreb, traduite de l'arabe d'En-Noweïri, "Journal Asiatique" 11 (1841), pp. 97-135 y 557-583. 
Mac Guckin de Slane, William, Description de l'Afrique septentrionale par El-Bekri, [ed. revisada y corregida], Argel, Adolphe Jourdan, 1913.

Mac Guckin de Slane, William, Ibn Khallikan's Biographical Dictionary, reimp. Beirut, Librairie du Liban, 1970.

Mac Guckin de Slane, William, Ibn Khaldoun. Histoire des berbères et des dynasties musulmanes de l'Afrique septentrionale, reimp. París, Librairie Orientaliste Paul Geuthner, 1978.

Maíllo, Felipe, Ibn al-Kardabus. Historia de Al-Andalus, Madrid, Akal, 1986.

Menéndez Pidal, Juan, Leyendas del último rey godo, II. Don Rodrigo y la Caba, "Revista de Archivos, Bibliotecas y Museos" 10 (1904), pp. 279-301.

Menéndez Pidal, Ramón, Primera Crónica General de España, reimp. Madrid, Gredos, 1977.

Molina, Luis, Una descripción anónima de Al-Andalus, Madrid, Consejo Superior de Investigaciones Científicas, 1983.

Montenegro, Julia; Castillo, Arcadio del, Don Pelayo y los orígenes de la Reconquista: Un nuevo punto de vista, "Hispania" 52 (1992), pp. 5-32.

Montenegro, Julia; Castillo, Arcadio del, Análisis crítico sobre algunos aspectos de la historiografía del reino de Asturias, "Hispania" 54 (1994), pp. 397-420.

Montenegro, Julia; Castillo, Arcadio del, Precisiones sobre Ceuta antes de la conquista musulmana (siglos VI-VIII), "Byzantion" 67 (1997), pp. 70-88.

Montenegro, Julia; Castillo, Arcadio del, La expedición de Abd Al-Malik Ibn Qatan Al-Fihri a los Pirinaica iuga en el Anónimo Mozárabe de 754, "Hispania" 64 (2004), pp. 185-201.

Montenegro, Julia; Castillo, Arcadio del, Carmen Cardelle de Hartmann (ed.), Victoris Tunnunensis Chronicon cum reliquiis ex Consularibus Caesaraugustanis et Iohannis Biclarensis Chronicon, with An Historical Commentary on the Consularia Caesaraugustana and Iohannis Biclarensis Chronicon by Roger Collins, Turnhout, Brepols, 2001, "Revue Belge de Philologie et d'Histoire" 82 (2004), pp. 1059-1063.

Montenegro, Julia; Castillo, Arcadio del, Theodemir's Victory over the Byzantines in the Joint Reign of Egica and Witiza: A Reference by the Chronicle of 754, "Byzantion" 74 (2004), pp. 403-415.

Montenegro, Julia; Castillo, Arcadio del, La campaña de Muza en el Noroeste en el año 713 y la capitulación de Astorga, "Estudios de Historia de España" 9 (2007), pp. 11-27.

Montenegro, Julia; Castillo, Arcadio del, Le règne de Rodéric, Akhila II et l'invasion musulmane de la péninsule Ibérique, "Francia" 34/1 (2007), pp. 1-17.

Monumenta Germaniae Historica. Auctores Antiquissimi, Berlín, Societas apariendis fontibus rerum germanicarum Medii Aevi, 1894.

Pellissier de Reynaud, Edmond; Rémusat, Jean Pierre Abel, Exploration scientifique de l'Algérie pendant les années 1840, 1841, 1842. Sciences historiques et géographiques. Histoire de l'Afrique de Mohammed ben Abi el-Raïni elKaïrouani, París, Imp. Royale, 1845.

Penelas, María Teresa, La conquista de Al-Andalus, Madrid, Consejo Superior de Investigaciones Científicas, 2002.

Puyol, Julio, Crónica de España por Lucas, obispo de Tuy. Primera edición del texto romanceado, conforme a un códice de la Academia, Madrid, Real Academia de la Historia, 1926.

Ribera, Julián, Historia de la conquista de España de Abenalcotía el Cordobés, Madrid, Real Academia de la Historia, 1926.

Saavedra, Eduardo, Estudio sobre la invasión de los árabes en España, Madrid, El Progreso Editorial, 1892.

ANUARIO de Estudios Medievales, 42/2, julio-diciembre 2012, pp. 755-769

ISSN 0066-5061, doi:10.3989/aem.2012.42.2.16 
Sánchez-Albornoz, Claudio, ¿Muza en Asturias? Los musulmanes y los astures trasmontanos antes de Covadonga, en Orígenes de la nación española. Estudios críticos sobre la Historia del reino de Asturias, Oviedo, Instituto de Estudios Asturianos, 1972, vol. I, pp. 459-484 (reimp. de la monografía aparecida en las Publicaciones del Centro Asturiano de Buenos Aires en 1944: la reimpresión tiene una errata en el título de "árabes" por "astures").

Sánchez-Albornoz, Claudio, Itinerario de la conquista de España por los musulmanes, "Cuadernos de Historia de España" 10 (1948), pp. 21-74 (reimp. en Orígenes de la nación española, vol. I, pp. 413-458).

Sánchez-Albornoz, Claudio, Frente a unas páginas erróneas sobre la conquista de España por los musulmanes, "Cuadernos de Historia de España" 49-50 (1969), pp. 294-309 (reimp. en Orígenes de la nación española, vol. I, pp. 487-499 y en Estudios polémicos, Madrid, Espasa Calpe, 1979, pp. 40-56).

Santiago Simón, Emilio de, Un fragmento de la obra de Ibn al-Shabbat (s. XIII) sobre Al-Andalus, "Cuadernos de Historia del Islam" 5 (1973), pp. 5-93.

Santos Coco, Francisco, Historia Silense, Madrid, Junta para la ampliación de estudios e investigaciones científicas. Centro de Estudios Históricos, 1921.

Schott, Andreas, Hispaniae illustratae seu rerum urbiumque Hispaniae, Lusitaniae, Aethiopiae et Indiae Scriptores varii, Frankfurt, Claudius Marnius et heredes Iohannis Aubrii, 1603.

Schott, Andreas, Hispaniae illustratae seu urbium rerumque hispanicarum, academiarum, bibliothecarum, clarorum denique in omni disciplinarum genere Scriptorum Actores varii Chronologi, Historici, Frankfurt, Claudius Marnius et heredes Iohannis Aubrii, 1608.

Sebag, Paul, Les expéditions maritimes arabes du VIII ${ }^{e}$ siècle, "Les cahiers de Tunisie" 8/31 (1960), pp. 73-82.

Seco de Lucena, Luis, Al-Qalqashandi, Valencia, Anubar, 1975.

Sezgin, Fuat, Geschichte des arabischen Schrifttums, Leiden, E.J. Brill, 1967.

Taha, Abdulwahid Dhanun, The Muslim Conquest and Settlement of North Africa and Spain, Londres-Nueva York, Routledge, 1989.

Tornberg, Carl Johan (ed.), Ibn-El-Athiri chronicon quod perfectissimum inscribitur, Leiden, E.J. Brill, 1870.

Ubieto Arteta, Antonio, Crónica Najerense, Valencia, Anubar, 1966.

Vallvé, Joaquín, Nuevas ideas sobre la conquista árabe de España. Toponimia y onomástica, "Al-Qantara" 10 (1989), pp. 51-150.

Fecha de recepción del artículo: octubre 2011

Fecha de aceptación y versión final: abril 2012 
